\title{
Introduction to the special issue
}

\author{
Jesus T. Pastor $\cdot$ Juan Aparicio $\cdot$ Luis Orea
}

Published online: 15 August 2013

(c) Springer Science+Business Media New York 2013

\section{Knox Lovell's profile}

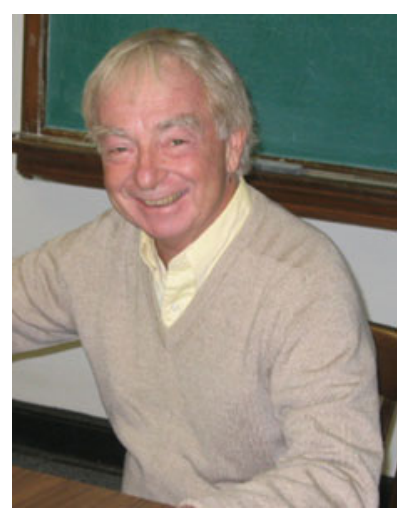

Professor Knox Lovell was honoured by the University Miguel Hernández of Elche with a PhD Honoris causa in October 2010. My proposal was approved by the Board of Governors of my University and our research group decided to organize at the same time a Workshop in Elche for all the scholars that have had some academic or scientific relationship with Prof. Lovell. Prof. Lovell attracted as many as 24 additional persons all over the world, friends and collaborators, that have dropped their everyday obligations in order to assist this well-deserved tribute. Prof. Robin was there and, as Editor in Chief of the Journal of

J. T. Pastor $(\bowtie) \cdot$ J. Aparicio

Center of Operations Research (CIO), Miguel Hernandez

University of Elche, Avda. de la Universidad s/n, 03202 Elche,

Alicante, Spain

e-mail: jtpastor@umh.es

\section{Orea}

Departamento de Economía, Facultad de Economía y Empresa, Universidad de Oviedo, Avda. del Cristo s/n, 33006 Oviedo, Spain
Productivity Analysis (JPA) he agreed to edit a special issue in honor of Prof. Lovell taking into account his relevant merits and the specific fact that he has been the Editor in Chief of JPA for a whole decade (1992-2002). I was proposed as Guest Editor and we incorporated as Associate Guest Editors two young Spanish distinguished scholars, Luis Orea (Universidad de Oviedo) and Juan Aparicio (Universidad Miguel Hernandez). Curiously enough, Prof. Lovell has been distinguished this year for the second time with a PhD Honoris Causa by the University of Liege, Belgium, thanks to the proposal made by Prof. Sergio Perelman.

In addition to his extensive scientific production-he is author or co-author of more than 100 papers published in high impact journals like the Journal of Econometrics, Management Science, Journal of Economic Theory, European Journal of Operational Research, Economic Journal, Annals of Operations Research, Operations Research Letters and Economic Theory, co-author of 4 books and co-editor of another 6-Knox has been Associate Editor of prestigious distinct journals like Operations Research and Management Science. Presently he belongs on the scientific committees of the three most relevant conferences in the world dedicated to efficiency and productivity (the European, North American and Asian), and he organized in the recent past three "Georgia Productivity Workshops" at his own university, in 1994, 1996 and 1998. His dedication to teaching under- and postgraduate students is more than noteworthy, having trained a substantial quantity of doctoral candidates, and participating in tribunals to judge doctoral theses on nine countries all over the world. What's more, he has been visiting Professor at the universities of British Columbia, Pennsylvania, Adelaide and Odense. His consulting efforts are also relevant, given that he has been employed by the United States Department 
of Justice, United State Army Recruiting Command, Federation of Credit Unions, Australian Productivity Commission, and the corporations AT\&T and KPMG.

As if this were insignificant, from the academic point of view, Professor Lovell had the wisdom to co-author two papers published in the Journal of Econometrics (Aigner, Lovell \& Schmidt, 1977 and Jondrow, Lovell, Materov and Schmidt, 1982) that established the fundamentals of a new investigative field, that of stochastic analysis of efficiency, also known as SFA or Stochastic Frontier Analysis. Moreover, he has published two books that have been cited innumerable times and themselves become classics. The first (1985, with Färe and Grosskopf, and then re-edited in 1994) deals with efficiency analysis, while the second relates to stochastic analysis of efficiency (2000, with Kumbhakar). Parallel to stochastic analysis, the nonparametric analysis of efficiency, known as DEA (Data Envelopment Analysis), was developed by professors Charnes and Cooper. Professor Lovell likes to remember that he was the first SFA representative to come into contact with people from DEA, at a conference he imparted in 1981 at the ORSA/TIMS meeting in Toronto. Aside from having to withstand a barrage of criticism from both Charnes as well as Cooper, they became permanent friends. Furthermore, Prof. Lovell organized a conference in 1988 under the auspices of the US National Science Foundation that united the leading experts on the two schools of thought. The leading research from that conference was published in a special edition of the Journal of Econometrics in 1990. To this day, some of this research still remains within the top 50 cited economics papers of all time.

To here, the outstanding professional profile of Prof. Lovell is outlined. His human side is nothing less, and within this, I will include his pastimes. Basically, I define Knox as an impassioned individual.

There is passion in his scientific work, to which he dedicates all the time necessary. I recall the first stay I made at his university, in 1994. Impressive to me was the tidiness of his research and the tremendous amounts of it. It was a pleasure to work in that environment, where everything was at hand and any doubt could be cleared up or consulted with ease.

Lovell Knox has a passion for travelling to and assisting conferences and seminaries. This gives him the opportunity to meet and be met by people with similar professional interests. More than half of his co-authors are travelers like him, and many of them have become his friends. He has visited many of us at our universities, and he has received us at his. He is, without a doubt, a very beloved person. And I am not alone in thinking like this. In fact, he met his actual happy Australian wife in 1995 at a conference, in
Armidale, Australia, and since then they have been inseparable.

$\mathrm{He}$ is passionate for his students. I remember that on days when he had class at 8 o'clock in the morning he would wake at five to make sure everything was properly in order. At 10 a.m. the class would conclude, but he frequently accompanied students to his office to resolve doubts they might have or to recommend further study material. Only one additional point: Prof. Lovell has directed 25 doctoral thesis.

Professor Knox also has a passion for living. "The university environment is closed off; therefore I enjoy going out in the evening to have contact with other kinds of people." He mingled with farmers, librarians, musicians, in addition to other academics sharing similar interests. Music was his umbilical cord, as well as NBA basketball games, NASCAR races and bier.

Finally is his passion for jazz music. Professor Lovell retired 6 years ago, and went to Australia to live with his lovely wife. In addition to being named Professor Emeritus of the University of Georgia, he has been named Honorary Professor at the University of Queensland, in Brisbane, Australia, where he presently resides. "My retirement simply means that I have ceased working in the classroom; I have not retired from Academia. My research continues at my new Australian university, and I continue travelling and participating in conferences and seminars". Curiously enough, the absence from the classroom has allowed him to broadcast his passion for jazz. For 6 years, he has worked at radio station $4 \mathrm{ZzZ}$ in Brisbane, presenting a weekly show dedicated to jazz. "A radio program is similar to teaching a course; you need to study and sometimes research in order to compile good material, you need to know what you are talking about and, finally, you need to have the ability to communicate it. The only differences now are that I have a far superior weekly audience than would have ever fit any lecture hall, I cannot see my radio listener, and they can make me disappear if they do not enjoy the show." This is, in a few broad strokes, the professional and personal profile of Professor Knox Lovell: a relevant scientist and a magnificent person.

\section{Contributions in honor of prof. Knox Lovell: a summary}

As highlighted in our 'Call for Papers', this special issue of the Journal of Productivity Analysis was conceived to gather theoretical or empirical contributions devoted to the measurement of efficiency and productivity. There was a satisfactory response in the number and high quality of manuscripts submitted, as well as the variety of topics 
addressed. An outline of all the contributions included in this issue is given below.

Let us first revise the papers focusing on methodological aspects. We will start with the paper written by Zofio, Pastor and Aparicio that deals with selecting a proper direction to measure firms' inefficiency when estimating (or computing) directional distance functions. Contrary to previous approaches, the authors advocate using market prices to select the directional vector, and make the choice of the direction leading to profit efficiency endogenous. An interesting feature of the proposed methodology for measuring profit efficiency is that profit inefficiency is categorized as either technical or allocative, but not both, as usually seen in literature. The advantage of the proposed framework is that the advice given to managers about the input and output adjustments they have to undertake to attain overall efficiency are univocal. The authors implement and illustrate the analytical model by way of DEA techniques, and introduce the necessary optimization programs for profit inefficiency measurement. Related to this topic, the paper by Färe, Grosskopf and Whittaker suggests a method within the DEA framework for estimating directional distance functions with endogenously determined direction vectors. In the most usual scenario, the researcher selects the directional (reference) vector to be used, with the calculated inefficiency score dependent on that choice. In addition, some reference vectors are more usual than others like, for example, considering the observed vector of inputs and outputs as directional vector. In contrast to the standard approach, Färe et al. endogenize the selection of the directional vector (optimizing over it) in order to determine the value of the directional distance function and, therefore, they obtain the reference vector as an optimal solution of the directional distance function model.

In recent times, one of the hot topics in Data Envelopment Analysis is weight restrictions. This methodology overcomes two well-known weaknesses of linear programming-based techniques for estimating technical efficiency: the occurrence of zero weights (shadow prices) and the existence of too many efficient units. In fact, they are the fundamental reasons for introducing weight constraints in DEA models. In this respect, the paper by Forsund is a critical revision of all the literature that deals with weight restrictions, from Thompson et al. in 1986 to the present, pointing out the strengths and weaknesses of each approach.

Another methodological paper, by Pastor, Aparicio, Monge and Pastor, extends an earlier work dealing with extrapolation issues in nonparametric methods for the assessment of relative technical efficiency under constant returns to scale (CRS). To avoid extrapolation outside of the observed data set in this setting, this paper proposes new models based on the notion of bounded technologies.
In particular, the authors show that under free disposability of inputs and outputs, CRS bounded additive models require a double set of slacks to properly characterize all the Pareto-efficient points associated to the bounded technology. This is the first example of DEA models that need a double set of slacks in their formulation.

Regarding methodological contributions from the perspective of the parametric approach, we have Amsler, Leonard and Schmidt who consider parametric frontier models where the error is purely one-sided. Unlike the traditional stochastic frontier model or non-parametric deterministic frontier models (e.g., free disposal hull and data envelopment analysis models), methods of inference for the estimated levels of technical inefficiency have not been established yet for parametric frontier models. The authors show that exact (finite sample) inference is possible when the frontier and the distribution of the one-sided error are known up to the values of some parameters, and errors satisfy a "scaling condition" that holds for many commonly-assumed distributions, including half-normal and exponential. In other cases, exact inference is still possible, but simulation or resampling methods (bootstrap) are needed to calculate the critical values.

On the other hand, the paper by Kumbhakar, Asche and Tveteras deals with the estimation of production technology when the choice of both inputs and outputs is endogenous. They address the endogeneity issue by defining a system of equations under maximization of return to the outlay that can be consistently estimated if input and output prices (assumed to be exogenous) are available. The authors use a panel of Norwegian fishing trawler data to illustrate their model. Fisheries are often recognized as a sector which has significant overcapacity and technical inefficiency due to factors such as skipper effects, diversified fleets with slow renewal of capital and regulations. Indeed, their empirical results show that the average overall economic efficiency is found to be around $60 \%$. The authors also find evidence of increasing technical change, starting from technical regress in the early years.

The contribution to this special issue by O'Donnell and Nguyen is a methodological paper with an application to 116 Queensland public hospitals for the 1996-2004 period. This paper shows how econometric methods may be used for estimating economically efficient prices of individual hospital services. The suggested method, which is flexible and robust, is based on using linear programs to construct a quantity index. From this index, the authors show how distance functions can be rewritten in the form of a conventional SFA model in which all the explanatory variables are exogenous - a result that is not easy to achieve by other means.

We turn next to empirical papers, starting with a couple of papers devoted to hospital applications. A difficult 
question to answer when health care is evaluated through DEA is how to incorporate quality factors. In this special issue, Ferrier and Trivitt have shown that adjusting for quality clearly changes the efficiency scores of the hospitals, and also the magnitude of the change depends on which quality adjustment method is used. In addition, these authors show that adjusting for outcome quality appears to be more important than adjusting for process quality. In another paper, Rodriguez-Alvarez, Roibas-Alonso and Wall analyze the response of decentralized health services to demand uncertainty and the role of political parties in the Spanish public health system, using SFA models. Over the last two decades, responsibility for the public health system in Spain has been transferred mostly to regional authorities. In this sense, it seems interesting to study whether regions with control over their hospitals acted differently to central authorities in terms of reserving service capacity to deal with demand uncertainty. With respect to the results, the authors found differences in the way resources are managed by central government and regional authorities. They also found differences between the decentralized authorities themselves, depending upon the political party in power.

Banking is also one of the topics included in this issue. Curi, Guarda, Lozano-Vivas and Zelenyuk use bootstrap with DEA and a second-stage regression in order to study whether home or host country factors may explain differences in efficiency among foreign banks operating in the Luxembourg financial center. As an innovation in the field of international bank efficiency, the authors take into account the relevant regulatory scheme applied to foreign banks according to their organizational form. The results suggest that the home-host regulation scheme applied to banks operating in financial centers is not successful in fostering bank efficiency, and bank efficiency is better explained by bank-specific characteristics (asset diversification, size and capitalization). On the other hand, the paper by Huang and $\mathrm{Fu}$ intends to shed some light on the extent of the potential benefits associated with two recent agreements in terms of financial cooperation between Taiwan and China. To achieve this objective, the authors estimate a metafrontier cost function and examine the determinants of (cost) technological gaps between the cost frontiers of banks in Taiwan and China. The empirical results indicate that programs related to changes directed toward a better bank production environment (e.g., a lower market concentration ratio and better democracy and corruption control) will enhance the bank's cost frontier and will thus narrow technological cost gaps.

Glass, Kenjegalieva and Sickles examine patterns of total factor productivity (TFP) change for two measures of congestion and two measures of the monetary value of congestion for a set of large US cities for the 1982-2007 period, during which the value of urban roadway congestion in real terms increased by over $50 \%$. The authors use Stochastic Frontier Analysis and conclude that average TFP growth is characterized by an upward trend. Also, they show that recent innovative policies have been effective, for example, ramp metering, incentives to carpool, etc.

Gaganis, Hasan and Pasiouras contribute to this issue with a paper that studies the relationship between efficiency change and stock returns in the insurance industry for the first time. While the authors find a positive relationship between profit efficiency change and market adjusted stock returns, there is no evidence that cost efficiency change is associated with stock returns. The evidence provided in this paper suggests that security analysts, firm managers, investors and other interested parties should be interested in efficiency performance measures as they seem to offer more information on firms' profits than traditional indicators. This paper is also of interest to numerous researchers as the obtained positive relationship between profit efficiency and stock returns provides a market-based test of the efficiency methodologies themselves and of the concepts underlying efficiency measurement.

Following a long period of sustained productivity growth, Australian coal mining experienced a period of productivity decline which began at the turn of the twentyfirst century. First estimates from the Australian Bureau of Statistics (ABS) suggested that productivity had declined in this sector by $24 \%$ over 6 years from its peak in 2000/2001. In their paper entitled "Productivity Decline in Australian Coal Mining", Lovell and Lovell try to shed light on the causes and financial implications of this remarkable, but perhaps unreal, productivity decline in one of the most important industries in the entire Australian economy. The authors first revise the data used previously and apply alternative methodologies to re-estimate the magnitude of the decline. Considerable shrinkage in the estimated productivity decline is found when they compare estimates of the decline obtained from value added and gross output frameworks due to the importance of purchased intermediate inputs in this economic sector.

Finally, Mosheim explores the complex link between economic growth and its environmental impact (measured in $\mathrm{CO}_{2}$ emissions) in two regions which have been similarly affected by environmental change, but with different development histories. This aim is achieved by decomposing the so-called Environmental Kuznets Curve (EKC) into three environmental effects. Unlike previous studies, the various effects are obtained from a so-called shadow distance function that is made environmentally sensitive by including both desirable and undesirable outputs. The results obtained in this paper highlight the importance of socioeconomic and institutional differences across 
countries to explain environmental outcomes in both regions. Thus, different policy responses are needed in both regions to achieve environmental improvements. For instance, this study suggests that amelioration of income inequality in some countries may yield larger environmental improvements than overall progression in wealth. 